\title{
Sub-MIC Tylosin Inhibits Streptococcus suis Biofilm Formation and Results in Differential Protein Expression
}

\author{
Shuai Wang ${ }^{1}$, Yanbei Yang ${ }^{1}$, Yulin Zhao ${ }^{1}$, Honghai Zhao ${ }^{2}$, Jingwen Bai ${ }^{1}$, Jianqing Chen ${ }^{1}$, \\ Yonghui Zhou ${ }^{1}$, Chang Wang ${ }^{1}$ and Yanhua $L^{1{ }^{1 *}}$ \\ ${ }^{1}$ Department of Veterinary Pharmacy, College of Veterinary Medicine, Northeast Agricultural University, Harbin, China, \\ ${ }^{2}$ Department of Biotechnology, Heilongjiang Vocational College for Nationalities, Harbin, China
}

OPEN ACCESS

Edited by:

Etienne Giraud,

Institut National de la Recherche

Agronomique, France

Reviewed by:

Rui Vitorino,

University of Aveiro, Portugal

Raymond Allan,

University of Southampton, UK

*Correspondence:

Yanhua $L i$

liyanhua1970@163.com

Specialty section:

This article was submitted to Antimicrobials, Resistance and

Chemotherapy,

a section of the journal

Frontiers in Microbiology

Received: 19 November 2015

Accepted: 11 March 2016

Published: 30 March 2016

Citation:

Wang S, Yang Y, Zhao Y, Zhao H, Bai J, Chen J, Zhou Y, Wang C and Li Y (2016) Sub-MIC Tylosin Inhibits

Streptococcus suis Biofilm Formation and Results in Differential Protein

Expression. Front. Microbiol. 7:384 doi: 10.3389/fmicb.2016.00384
Streptococcus suis (S.suis) is an important zoonotic pathogen that causes severe diseases in humans and pigs. Biofilms of $S$. suis can induce persistent infections that are difficult to treat. In this study, the effect of tylosin on biofilm formation of $S$. suis was investigated. 1/2 minimal inhibitory concentration (MIC) and 1/4 MIC of tylosin were shown to inhibit $S$. suis biofilm formation in vitro. By using the ITRAQ strategy, we compared the protein expression profiles of $S$. suis grown with sub-MIC tylosin treatment and with no treatment. A total of 1501 proteins were identified by iTRAQ. Ninety-six differentially expressed proteins were identified (Ratio $> \pm 1.5, p<0.05$ ). Several metabolism proteins (such as phosphoglycerate kinase) and surface proteins (such as $A B C$ transporter proteins) were found to be involved in biofilm formation. Our results indicated that $S$. suis metabolic regulation, cell surface proteins, and virulence proteins appear to be of importance in biofilm growth with sub-MIC tylosin treatment. Thus, our data revealed the rough regulation of biofilm formation that may provide a foundation for future research into mechanisms and targets.

Keywords: proteomics, S. suis, biofilms, tylosin, iTRAQ

\section{INTRODUCTION}

Streptococcus suis (S. suis) is an important zoonotic pathogen that causes a wide range of diseases in pigs, including meningitis, septicaemia, pneumonia, endocarditis, and arthritis (Gottschalk et al., 2010). In addition, this pathogen is an emerging zoonotic agent and an important public health issue in East and Southeast Asia (Sriskandan and Slater, 2006; Gottschalk et al., 2007). During a single outbreak in China in 2005, more than 200 human cases of S. suis were reported, with a death total of 39 (Yang et al., 2006). Current studies show that $S$. suis can cause persistent infections by forming biofilms in vivo (Wang et al., 2011).

Biofilms are assemblages of microorganisms characterized by cells that are irreversibly attached to a substratum and embedded in a matrix of self-produced extracellular polymeric substances such as exopolysaccharides (EPS), proteins, nucleic acids and other substances; this type of sessile community-based existence is a critical characteristic for bacterial persistence (Davey and O'Toole, 2000). The physical and biological properties of the biofilm, such as slow growth and mechanical barrier, have a substantial role in the development of increased antimicrobial tolerance. Because the bacteria in chronic infections are aggregated and are in close proximity, genes coding for resistance 
to antimicrobials can be passed horizontally from one bacterium to the another (Bjarnsholt et al., 2013). The bacteria in biofilms could be 1000-times more difficult to kill by antibiotics than the same organism growing planktonically (Gilbert et al., 1997). Therefore, the control of biofilms is understood to be crucial.

Apart from surgical intervention (when applicable), antibiotics are the main option for the treatment of biofilm infections (Bjarnsholt et al., 2013). Previous studies showed that macrolides successfully inhibited Staphylococcus aureus biofilm formation and reduced its virulence when used at sub-inhibitory concentrations (Fujimura et al., 2008). In addition, a subminimal inhibitory concentration of erythromycin can inhibit $S$. suis biofilm formation (Zhao et al., 2015). Tylosin, a macrolide antibiotic produced by Streptomyces fradiae, is widely used as a veterinary medicine. However, there is still not much effective research of sub-MIC tylosin inhibiting biofilm formation of $S$. suis in vitro.

At present, most of the available information regarding biofilm formation by drug intervention is based on transcriptomic analyses. However, a limitation of transcriptomic analysis for identifying biofilm-regulated gene network raised concerns among investigators. The method of proteomics is thought to be an essential complement to transcriptomic analysis for discovering key regulators of biofilm (Sauer, 2003). Different immunogenic components of planktonically grown $S$. suis proteins such as secreted or cell wall-associated proteins had been studied by using immunoproteomic assays (Zhang and Lu, 2007a,b; Geng et al., 2008; Zhang et al., 2008). Additionally, our lab found that quorum-sensing played a crucial role leading to biofilm formation through quantitative proteomic analysis of $S$. suis biofilm inhibited by sub-MIC erythromycin treatment in vitro (Zhao et al., 2015). However, there are no reports regarding the proteomic analysis of sub-MIC tylosin inhibiting biofilm formation of S. suis in vitro.

We identified several proteins in sub-MIC tylosin inhibiting biofilm formation of $S$. suis by using iTRAQ technology in this study. The findings from the present study may provide a theoretical foundation for therapy of S. suis biofilm infection and provide references for finding new potential therapeutic targets.

\section{MATERIALS AND METHODS}

\section{Growth of S. suis Planktonic Cells}

S. suis (ATCC 700794) was grown in Todd-Hewitt yeast Broth (THB; Summus Ltd., Harbin, Heilongjiang, China) for $16-18 \mathrm{~h}$ at $37^{\circ} \mathrm{C}$ with constant shaking for biofilm assays (Wang et al., 2011).

\section{Observation by Scanning Electron Microscopy (SEM)}

Mid-exponential growth phase cultures of S. suis ATCC 700794 were adjusted to an optical density of 0.1 at $600 \mathrm{~nm}$ (OD600). Then, $2 \mathrm{~mL}$ cultures were transferred to the wells of a 6-well microplate containing an $11 \times 11 \mathrm{~mm}$ sterilized rough glass slide (Mosutech Co., Ltd., Shanghai, China) on the bottom. After culturing for $72 \mathrm{~h}$ at $37^{\circ} \mathrm{C}$ without shaking, the glass slide was removed with tweezers, and the biofilms on the rough glass slide were washed with sterile PBS. The remaining biofilms were fixed with fixative solution $[4 \%(\mathrm{w} / \mathrm{v})$ paraformaldehyde, $2.5 \%(\mathrm{w} / \mathrm{v})$ glutaraldehyde, $2 \mathrm{mM} \mathrm{CaCl}$ in $0.2 \mathrm{M}$ cacodylate buffer, $\mathrm{pH} 7.2$ ] for $6 \mathrm{~h}$ and washed three times with $0.1 \mathrm{M}$ PBS $10 \mathrm{~min}$ each, then fixed in $2 \%$ osmium tetroxide containing $2 \mathrm{mM}$ potassium ferrocyanide and $6 \%(\mathrm{w} / \mathrm{v})$ sucrose in cacodylate buffer. The samples were dried, gold sputtered with an ion sputtering instrument (current $15 \mathrm{~mA}, 2 \mathrm{~min}$ ) and observed using SEM (FEI Quanta, Netherland).

\section{Effect of Tylosin on Biofilm Formation Determined by the TCP Assay}

Mid-exponential growth phase cultures of $S$. suis were adjusted to 0.2 of OD600. Then, $100 \mu \mathrm{L}$ of cultures were added to each wells of a 96-well microplate with equal volume of tylosin solution with the final concentrations of $1 / 2 \mathrm{MIC}(0.25 \mu \mathrm{g} / \mathrm{mL}), 1 / 4$ MIC $(0.125 \mu \mathrm{g} / \mathrm{mL}), 1 / 8 \mathrm{MIC}(0.0625 \mu \mathrm{g} / \mathrm{mL})$, and 1/16 MIC $(0.03125 \mu \mathrm{g} / \mathrm{mL})$, respectively. In addition, a negative control (with THB alone) and a positive control (with bacteria alone) were also included. After incubation at $37^{\circ} \mathrm{C}$ for $72 \mathrm{~h}$ without shaking, the medium was removed by aspiration and the wells were washed three times with sterile physiological saline. The remaining attached bacteria were fixed with $200 \mu \mathrm{L}$ of $99 \%$ methanol (Guoyao Ltd., China) per well, and the plates were emptied after $15 \mathrm{~min}$ and left to dry. Then, the plates were stained for $5 \mathrm{~min}$ with $200 \mu \mathrm{L}$ of $2 \%$ crystal violet (Guoyao Ltd., China) per well. The excess stain was rinsed off by placing the plate under running tap water. After the plates were air dried, the dye bound to the adherent cells was resolubilized with $200 \mu \mathrm{L}$ of $33 \%(\mathrm{v} / \mathrm{v})$ glacial acetic acid (Guoyao Ltd., China) per well. The amount of released stain was quantified by measuring the absorbance at $570 \mathrm{~nm}$ with a microplate reader (DG5033A, Huadong Ltd., Nanjing, Jiangsu, China). The reported values are the means of three measurements. The experiments were performed in triplicate.

\section{Colony Forming Unit (CFU) Enumeration}

Overnight cultures of $S$. suis were adjusted to an OD 600 of 0.2 . Then, the bacteria were inoculated into 96-well microtiter plate wells containing $200 \mu \mathrm{L}$ of THB alone (untreated wells) or adding the tylosin solution with the final concentrations of $1 / 4 \mathrm{MIC}$ $(0.125 \mu \mathrm{g} / \mathrm{mL})$. In addition, a negative control (with THB alone) and a positive control (with bacteria alone) were also included. After incubation at $37^{\circ} \mathrm{C}$ for $72 \mathrm{~h}$ without shaking, the medium was removed by aspiration, and the wells were washed three times with sterile physiological saline. Biofilm cells were removed from wells by sonication for $5 \mathrm{~min}$ in $200 \mu \mathrm{L}$ of THB. The cell suspensions $(n=3)$ underwent 10 -fold dilutions in THB, and 100 $\mu \mathrm{L}$ of each dilution was spot plated onto THB soft-agar plates and incubated at $37^{\circ} \mathrm{C}$ for $24 \mathrm{~h}$. All the experiments were performed in triplicate.

\section{Preparation of Protein Extracts}

For biofilm cultures, S. suis was grown in THB in $100 \mathrm{~mm}$ polystyrene petri dishes at $37^{\circ} \mathrm{C}$ for $24 \mathrm{~h}$. Then, the supernatant was removed and the dishes were washed twice with Tris$\mathrm{HCl}$ buffer $(50 \mathrm{mM}, \mathrm{pH}$ 7.5). The biofilms were detached by scraping. After being sonicated for $5 \mathrm{~min}$ (Bransonic 220; Branson Consolidated Ultrasonic Pvt. Ltd., Australia), the cells were centrifuged at $12,000 \times \mathrm{g}$ for $10 \mathrm{~min}$ at $4^{\circ} \mathrm{C}$. Then, the cell 
pellets were washed twice with Tris- $\mathrm{HCl}$ buffer (Wang et al., 2012).

\section{Protein Digestion and iTRAQ Labeling}

Protein digestion was performed according to the reported FASP procedure (Wisniewski et al., 2009). In brief, $200 \mu \mathrm{g}$ of proteins at two different conditions (1/4 MIC of tylosin treated cells and nontreated cells) were added into $30 \mu \mathrm{L}$ STD buffer ( $4 \%$ SDS, $100 \mathrm{mM}$ DTT, $150 \mathrm{mM}$ Tris- $\mathrm{HCl} \mathrm{pH} 8.0$ ) and ultrafiltered (Microcon units, $30 \mathrm{kD}$ ) with UA buffer $(8 \mathrm{M}$ Urea, $150 \mathrm{mM}$ Tris- $\mathrm{HCl} \mathrm{pH}$ 8.0). To block reduced cysteine residues, $100 \mu \mathrm{L}$ $0.05 \mathrm{M}$ iodoacetamide was added into UA buffer and incubated for $20 \mathrm{~min}$ in the dark. The filters were washed three times with $100 \mu \mathrm{L}$ UA buffer and twice with $100 \mu \mathrm{L}$ DS buffer $(50 \mathrm{mM}$ triethylammoniumbicarbonate at $\mathrm{pH}$ 8.5). Finally, the proteins were digested with $2 \mu \mathrm{g}$ trypsin (Promega) in $40 \mu \mathrm{L}$ DS buffer at $37^{\circ} \mathrm{C}$ for $16-18 \mathrm{~h}$. Then, the resulting peptides were collected as a filtrate. The peptide content was estimated by UV light spectral density at $280 \mathrm{~nm}$ using an extinctions coefficient of 1.1 of $0.1 \%(\mathrm{~g} / \mathrm{l})$ solution calculated on the basis of the frequency of tryptophan and tyrosine in vertebrate proteins.

For the iTRAQ labeling, the peptides were labeled with the 8plex iTRAQ reagent by following the manufacturer's instructions (Applied Biosystems). Each iTRAQ reagent was dissolved in $70 \mu \mathrm{L}$ of ethanol and added to the respective peptide mixture. The peptides from the S. suis biofilms treated by tylosin were labeled with 115 isobaric reagent, and the peptides from the nontreated S. suis biofilms were labeled with 116 isobaric reagent. Then, the samples were multiplexed and vacuum dried. Three independent biological experiments were performed.

\section{Peptide Fractionation with Strong Cation Exchange (SCX) Chromatography}

SCX chromatography using the AKTA Purifier system (GE Healthcare) was used to fractionate the iTRAQ labeled peptides. After being reconstituted and acidified with $2 \mathrm{~mL}$ buffer A $\left(10 \mathrm{mM} \mathrm{KH}_{2} \mathrm{PO}_{4}\right.$ in $25 \%$ of $\left.\mathrm{ACN}, \mathrm{pH} 2.7\right)$, the peptides were loaded onto a PolySULFOETHYL $4.6 \times 100 \mathrm{~mm}$ column $(5 \mu \mathrm{m}$, $200 \AA$ A, PolyLC Inc., Maryland, U.S.A.). Then, the peptides were eluted at $1 \mathrm{ml} / \mathrm{min}$ with a gradient of $0-10 \%$ buffer B $(500 \mathrm{mM}$ $\mathrm{KCl}, 10 \mathrm{mM} \mathrm{KH}_{2} \mathrm{PO}_{4}$ in $25 \%$ of $\mathrm{ACN}, \mathrm{pH} 2.7$ ) for $2 \mathrm{~min}, 10$ $20 \%$ buffer B for $25 \mathrm{~min}, 20-45 \%$ buffer B for $5 \mathrm{~min}$, and $50-100 \%$ buffer B for $5 \mathrm{~min}$. The elution was monitored by absorbance at $214 \mathrm{~nm}$, and the fractions were collected after every $1 \mathrm{~min}$. The collected fractions ( $\sim 30$ fractions) were combined into 10 pools and desalted on C18 Cartridges [Empore ${ }^{\mathrm{TM}}$ SPE Cartridges C18 (standard density), bed I.D. $7 \mathrm{~mm}$, volume $3 \mathrm{ml}$, Sigma]. Each pooled fraction was concentrated by vacuum centrifugation and reconstituted in $40 \mu \mathrm{l}$ of $0.1 \%(\mathrm{v} / \mathrm{v})$ trifluoroacetic acid and stored at $-80^{\circ} \mathrm{C}$ for LC-MS/MS analysis.

\section{Liquid Chromatography (LC) Electrospray lonization (ESI) Tandem Ms (MS/MS) Analysis by $Q$ Exactive}

Experiments were performed on a $\mathrm{Q}$ Exactive mass spectrometer that was coupled to Easy nLC (Thermo Fisher Scientific). A sample $(10 \mu \mathrm{L})$ of each fraction was injected for the nano LCMS/MS analysis. The peptide mixture $(5 \mu \mathrm{g})$ was loaded onto a C18-reversed phase column (Thermo Scientific Easy Column, $10 \mathrm{~cm}$ long, $75 \mu \mathrm{m}$ inner diameter, $3 \mu \mathrm{m}$ resin) in buffer $\mathrm{A}$ $(0.1 \%$ formic acid $)$ and separated with a linear gradient of buffer B ( $80 \%$ acetonitrile and $0.1 \%$ formic acid) at $250 \mathrm{nl} / \mathrm{min}$ controlled by IntelliFlow technology for $140 \mathrm{~min}$. MS data were acquired using a data-dependent top 10 method dynamically choosing the most abundant precursor ions from the survey scan $(300-1800 \mathrm{~m} / \mathrm{z})$ for HCD fragmentation. Determination of the target value was based on predictive Automatic Gain Control (pAGC). The dynamic exclusion duration was 60 s. Survey scans were acquired at a resolution of 70,000 at $\mathrm{m} / \mathrm{z} 200$, and the resolution for HCD spectra was set to 17,500 at $\mathrm{m} / \mathrm{z} 200$. The normalized collision energy was $30 \mathrm{eV}$, and the underfill ratio, which specifies the minimum percentage of the target value likely to be reached at maximum fill time, was defined as $0.1 \%$. The instrument was run with the peptide recognition mode enabled.

\section{Sequence Database Searching and Data Analysis}

The MS/MS spectra were searched using the MASCOT engine (Matrix Science, London, UK; version 2.2) in the Proteome Discoverer 1.3 (Thermo Electron, San Jose, USA.) against the Uniprot S. suis fasta database $(38,369$ sequences, downloaded March 4th, 2013) and the decoy database. False discovery rates (FDR) were calculated by running all spectra against a decoy database using the MASCOT software. To identify proteins, the following options were used: Peptide mass tolerance $=20 \mathrm{ppm}$, MS/MS tolerance $=0.1 \mathrm{Da}$, Enzyme $=$ Trypsin, Missed cleavage $=2$, Fixed modification: Carbamidomethyl $(C)$, iTRAQ 8plex (K), iTRAQ 8plex (N-term), Variable modification: Oxidation (M). The quantification was performed based on the peak intensities of the reporter ions in the MS/MS spectra. The ratio of label 115 and 116 represents the expression of proteins with the protein identification confidence of a 1\% FDR (Unwin et al., 2010). The proteins were considered over expressed when the ITRAQ ratio was above 1.5 and under expressed when the ITRAQ ratio was lower than 0.67. The Proteome Discoverer tool was used to categorize the proteins detected by Gene Ontology (GO) annotation according to the cellular component, biological process and molecular function.

\section{RESULTS}

\section{Effect of Tylosin against Biofilm Formation In vitro by the TCP Assay}

We evaluated the action of tylosin on biofilm growth in vitro. The MIC against $S$. suis was $0.5 \mu \mathrm{g} \cdot \mathrm{mL}^{-1}$. Tylosin at $1 / 2 \mathrm{MIC}$ and $1 / 4$ MIC caused a significantly higher reduction in the biofilmforming ability of $S$. suis compared with positive control $(p<$ $0.05)$. However, there was no pronounced effect for $1 / 16$ MIC and $1 / 8 \mathrm{MIC}$ of tylosin on biofilm formation of $S$. suis $(p>0.05$; Figure 1). 


\section{Direct Observation of Biofilm Formation In vitro by Sem}

SEM analysis was performed to observe the $1 / 4$ MIC of tylosin treated cells and nontreated cells biofilm formation by $\mathrm{S}$. suis under same growth conditions. As shown in Figure 2A, the surface of the glass slide is almost entirely covered by the aggregates and microcolonies of $S$. suis when growth was carried out in the culture medium without tylosin. However, when the culture medium was added to $1 / 4$ MIC of tylosin, the biofilms were characterized by the presence of small clusters of cells interspersed amongst individual cells (Figure 2B). This result showed that the biofilm formation of $S$. suis was inhibited by the tylosin of $1 / 4$ MIC in vitro.

\section{Colony Forming Unit (CFU) Enumeration}

To better assess action of tylosin on biofilm quantitatively, the CFUs of S. suis were counted. The viability of S. suis treated with 1/4 MIC of tylosin was different from the viability of untreated S. suis. The number of CFUs/mL in treated biofilms $\left(5.3 \log _{10}\right.$ CFUs/mL) was significantly fewer than in nontreated biofilms (6.5 $\log _{10}$ CFUs $/ \mathrm{mL} ; p<0.05$ ). The number of CFUs/mL in treated biofilms $\left(5.3 \log _{10} \mathrm{CFUs} / \mathrm{mL}\right.$ ) was significantly fewer than in nontreated biofilms $\left(6.5 \log _{10}\right.$ CFUs/mL; $\left.p<0.05\right)$ (Figure 3). The findings demonstrated that $1 / 4$ MIC of tylosin remained effective in decreasing the viability of $S$. suis.
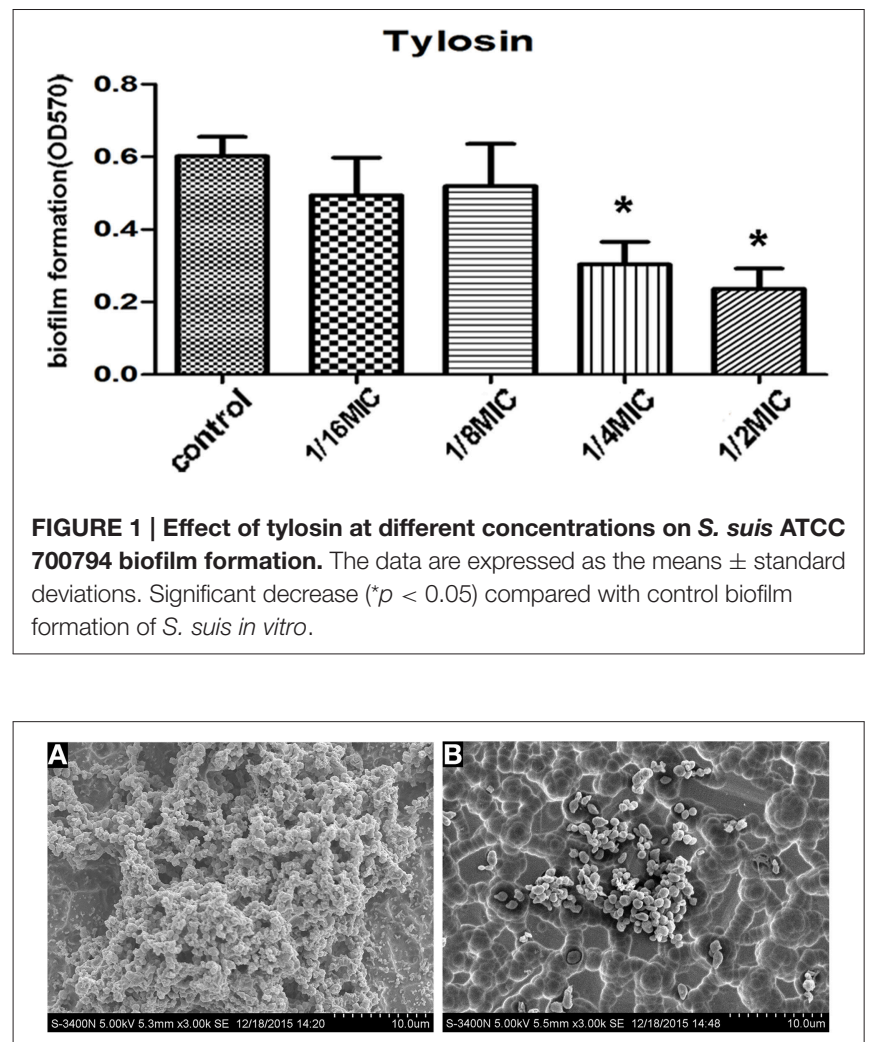

FIGURE 2 | (A) Biofilm formation of S. suis without tylosin. (B) Biofilm formation of $S$. suis with $1 / 4 \mathrm{MIC}$ tylosin treatment.

\section{Sub-MIC Tylosin Inhibits Biofilm Formation and Differentially Expressed Proteins by ITRAQ}

A total of 1501 proteins were identified by iTRAQ. Detailed information is shown in the Supplementary File. A ratio of proteins with $>1.5$ or $<0.67(p<0.05)$ was considered to be differentially expressed. Based on this criterion, 96 differentially expressed proteins were identified in 1/4 MIC tylosin treated cells and nontreated cells. Detailed information could is shown Table 1. These proteins were detected by GO annotation. Thirty-five proteins were deleted from the database. The remaining 61 proteins were classified into biological process, molecular function and cellular component (Figure 4). The results regarding the biological process were as follows: single-organism process $(8,13 \%)$, response to stimulus $(4$, $7 \%)$, localization $(4,7 \%)$, biological adhesion $(1,2 \%)$, cellular component organization or biogenesis $(6,10 \%)$, cellular process $(25,41 \%)$, biological regulation $(3,5 \%)$, metabolic process $(30$, $49 \%)$. The results regarding molecular function were as follows: binding $(29,48 \%)$, nucleic acid binding transcription factor activity $(1,2 \%)$, transporter activity $(3,5 \%)$, structural molecule activity $(5,8 \%)$, catalytic activity $(25,41 \%)$. The results regarding cellular component were as follows: organelle $(6,10 \%)$, virion (1, $2 \%)$, cell $(13,21 \%)$, extracellular region $(1,2 \%)$, membrane $(6$, $10 \%)$, macromolecular complex $(8,13 \%)$.

\section{DISCUSSION}

A TCP assay is based on the ability of bacteria to form biofilms on the bottom of tissue culture plates and is mainly used to identify the formation of bacterial biofilms (Mathur et al., 2006; Okajima et al., 2006; Presterl et al., 2007). Bacteria are grown in cell culture plates, and the quantity of a biofilm is detected by staining the wells with crystal violet according to the correlation between OD values and biofilm formation (Mathur et al., 2006).

To further confirm S. suis biofilm formation, the structure of the $S$. suis biofilm was identified by scanning electron microscopy

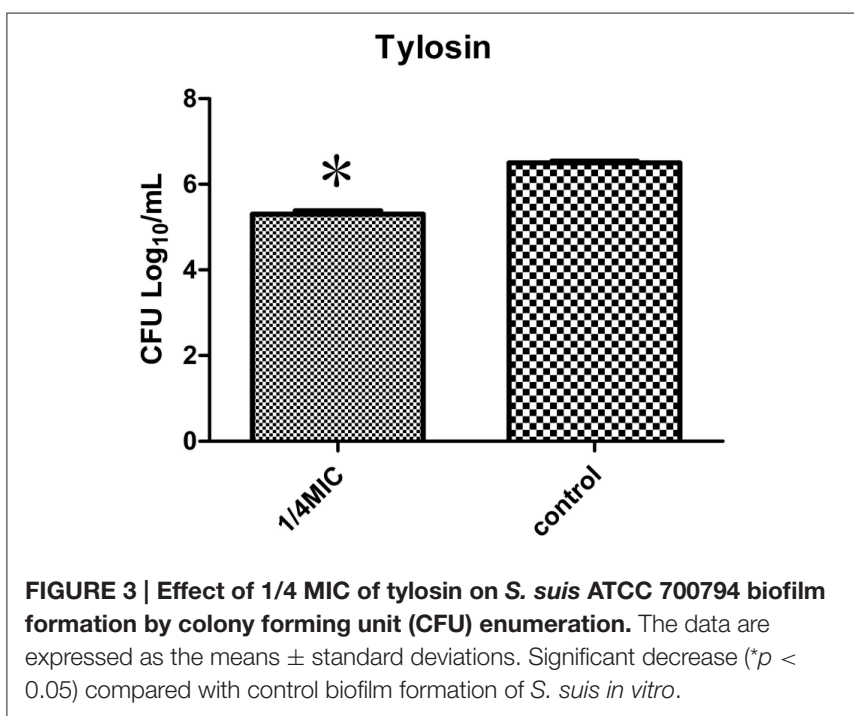


TABLE 1 | List of differentially expressed proteins in tylosin treated cells.

\begin{tabular}{|c|c|c|}
\hline Accession & Description & Fold change $^{a}$ \\
\hline G7SDH9 & Putative uncharacterized protein & 0.555777 \\
\hline A4W1G9 & $\begin{array}{l}\text { Phosphotransferase system cellobiose-specific } \\
\text { component IIC }\end{array}$ & 0.521547 \\
\hline G7SA24 & Cold-shock DNA-binding domain protein & 0.394546 \\
\hline F4EDP5 & Putative uncharacterized protein & 0.568016 \\
\hline R4NL31 & MF3-like protein & 0.63094 \\
\hline E9NQ29 & CPS16V & 0.452748 \\
\hline G5KZ73 & $\begin{array}{l}\text { NADH:flavin oxidoreductase/NADH oxidase family } \\
\text { protein }\end{array}$ & 0.459622 \\
\hline G7S4C2 & $\begin{array}{l}\text { Major membrane immunogen, } \\
\text { membrane-anchored lipoprotein }\end{array}$ & 0.643938 \\
\hline A8CUL3 & Integrase & 0.46773 \\
\hline G7SM99 & $\begin{array}{l}\text { Type I site-specific restriction-modification system, } \\
\text { R (Restriction) subunit and related helicase }\end{array}$ & 0.506277 \\
\hline G7SLJ0 & Putative competence-damage inducible protein & 0.564703 \\
\hline A4W1W3 & FOF1-type ATP synthase, subunit a & 0.586873 \\
\hline G7RZWO & Sugar $A B C$ transporter permease & 1.508325 \\
\hline G7S2T8 & Alcohol dehydrogenase & 0.610195 \\
\hline G7SDG9 & Laminin binding protein & 1.524593 \\
\hline R4NLJ6 & $\begin{array}{l}\text { Oligopeptide ABC transporter, periplasmic } \\
\text { oligopeptide-binding protein OppA }\end{array}$ & 0.644177 \\
\hline G7S371 & Fructose-bisphosphate aldolase & 0.623705 \\
\hline M1UGE2 & Uncharacterized protein & 0.647168 \\
\hline A4VZM2 & Cell cycle protein GpsB & 0.631018 \\
\hline A4W2D2 & Cation transport ATPase & 1.676356 \\
\hline G5L1V6 & 50 S ribosomal protein L9 & 0.6638821 \\
\hline G7SEP2 & Putative uncharacterized protein & 1.502566 \\
\hline A4VZ3 & tRNA dimethylallyltransferase & 1.510883 \\
\hline G7S5B8 & 3-isopropylmalate dehydrogenase & 1.513117 \\
\hline G7SA68 & UDP-N-acetylmuramate-alanine ligase & 0.656503 \\
\hline G5L098 & Transcriptional regulator Spx & 1.514636 \\
\hline E8UKC3 & Uncharacterized protein & 1.507837 \\
\hline G7SFU4 & Putative uncharacterized protein & 1.543591 \\
\hline A4V999 & DNA repair protein & 1.545594 \\
\hline A4W2Z7 & FMN-dependent NADH-azoreductase & 1.527496 \\
\hline F4EC05 & Putative uncharacterized protein & 1.57743 \\
\hline C6GNL8 & 30 S ribosomal protein S21 & 1.545471 \\
\hline K7ZNG8 & DNA recombination/repair protein (Fragment) & 1.558023 \\
\hline G7S3K5 & $\begin{array}{l}\text { ABC-type cobalt transport system, ATPase } \\
\text { component }\end{array}$ & 1.583854 \\
\hline G7SM56 & Ribosomal RNA small subunit methyltransferase $\mathrm{H}$ & 1.594936 \\
\hline A2VC24 & Muramidase-released protein & 1.579304 \\
\hline A4W3C1 & Putative phosphotyrosine protein phosphatase & 1.60975 \\
\hline G7S4U0 & Putative uncharacterized protein & 1.596783 \\
\hline G7SP92 & Putative uncharacterized protein & 1.658448 \\
\hline G7S7E3 & Helicase & 1.516925 \\
\hline M1VK55 & Glycosyltransferase & 1.662795 \\
\hline G7S3P9 & Putative uncharacterized protein & 1.673475 \\
\hline A4W106 & Signal transduction histidine kinase & 1.62492 \\
\hline BOMOG7 & Phosphomethylpyrimidine kinase (Fragment) & 1.633436 \\
\hline A5JSJ7 & Putative uncharacterized protein & 1.681661 \\
\hline G5L226 & $\begin{array}{l}\text { Type III restriction-modification system, restriction } \\
\text { endonuclease subunit }\end{array}$ & 1.697991 \\
\hline
\end{tabular}

TABLE 1 | Continued.

\begin{tabular}{|c|c|c|}
\hline Accession & Description & Fold change $\mathrm{a}^{\mathrm{a}}$ \\
\hline G7S7K4 & Putative uncharacterized protein & 1.645719 \\
\hline B9WY95 & Peptidase M20 & 1.647536 \\
\hline G7S4T2 & $\begin{array}{l}\text { Branched-chain alpha-keto acid dehydrogenase } \\
\text { subunit E2 }\end{array}$ & 1.673032 \\
\hline G5KX48 & $\begin{array}{l}\text { ABC-type uncharacterized transport system, } \\
\text { permease component }\end{array}$ & 1.705109 \\
\hline G7S178 & Putative uncharacterized protein & 1.774886 \\
\hline M1VDL7 & $A B C$ transporter permease protein & 1.942183 \\
\hline G7S6Z3 & Putative uncharacterized protein & 1.956584 \\
\hline J7KIA5 & $\begin{array}{l}\text { Abortive infection bacteriophage resistance } \\
\text { related protein }\end{array}$ & 1.999106 \\
\hline G7SJZ7 & Primosomal protein N' & 1.720079 \\
\hline G7SHW7 & Putative uncharacterized protein & 2.001559 \\
\hline Q9EZW2 & Elongation factor Tu (Fragment) & 1.739971 \\
\hline A4VJ5 & Uncharacterized protein & 2.141695 \\
\hline M1VJZ8 & Zeta toxin & 1.74309 \\
\hline G5L2VO & $\begin{array}{l}\text { NADPH:quinone reductase and related } \\
\text { Zn-dependent oxidoreductase }\end{array}$ & 1.79706 \\
\hline R4NU43 & $\begin{array}{l}\text { Aromatic amino acid aminotransferase gamma } \\
@ \text { N-acetyl-L,L-diaminopimelate } \\
\text { aminotransferase }\end{array}$ & 2.144605 \\
\hline A4W296 & Uncharacterized protein & 1.837367 \\
\hline G7SKQ0 & CHAP domain containing protein & 2.179882 \\
\hline B9WVD6 & Putative uncharacterized protein (Fragment) & 2.226792 \\
\hline G5L2N5 & L-fucose isomerase & 1.859887 \\
\hline B9WTA1 & Putative uncharacterized protein & 2.290848 \\
\hline B9WXU6 & $\mathrm{ABC}$ transporter related protein & 1.873566 \\
\hline G8DU82 & Transposase & 2.376768 \\
\hline G7S242 & Putative ABC transporter & 1.883471 \\
\hline A4VZ91 & 50 S ribosomal protein L32 & 1.915877 \\
\hline G7SDX6 & $50 S$ ribosomal protein $\mathrm{L} 7 / \mathrm{L} 12$ & 1.918196 \\
\hline G5KZ86 & $\begin{array}{l}\text { Phosphatidylserine/phosphatidylglycerophosphate/ } \\
\text { cardiolipin synthase-like protein }\end{array}$ & 1.965488 \\
\hline G7SIQ5 & Putative uncharacterized protein & 2.451703 \\
\hline G7S7J2 & Putative uncharacterized protein & 2.481527 \\
\hline G7SPA1 & Putative scaffolding protein & 2.584249 \\
\hline G7S7A9 & $\begin{array}{l}\text { FAD-dependent pyridine nucleotide-disulfide } \\
\text { oxidoreductase }\end{array}$ & 1.970356 \\
\hline G7S8Q2 & Peptidase M22 glycoprotease & 1.978772 \\
\hline M1TIM7 & $\begin{array}{l}\text { Methylated DNA-protein cysteine } \\
\text { methyltransferase }\end{array}$ & 2.161583 \\
\hline G7SBK2 & Elongation factor Ts & 2.266517 \\
\hline M1VE47 & Fic/DOC family protein & 2.606274 \\
\hline M1UFP9 & Thiamine-phosphate synthase & 2.298028 \\
\hline G7S535 & Fructose-6-phosphate aldolase & 2.553516 \\
\hline G5L351 & NsuB & 2.694988 \\
\hline B9WUV5 & Transcriptional regulator, DeoR family & 2.65073 \\
\hline R4NW55 & $\begin{array}{l}\text { Plasmid replication protein Rep and AAA-class } \\
\text { ATPase domain protein }\end{array}$ & 2.779765 \\
\hline G7RZ18 & Sortase-like protein & 2.791504 \\
\hline S6B433 & RecN protein (Fragment) & 3.007243 \\
\hline G5KZR3 & Glutathione S-transferase & 3.262393 \\
\hline R4NLK5 & SSU ribosomal protein S1p & 3.46851 \\
\hline R4NWB6 & Uncharacterized protein & 8.306942 \\
\hline
\end{tabular}

(Continued) 
TABLE 1 | Continued.

\begin{tabular}{llc}
\hline Accession & Description & Fold change $^{\text {a }}$ \\
\hline G5L259 & $\begin{array}{l}\text { NADP-dependent glyceraldehyde-3-phosphate } \\
\text { dehydrogenase, putative }\end{array}$ & 2.781098 \\
D5AFN4 & Xaa-Pro dipeptidyl-peptidase & 3.095053 \\
G7SMG3 & Elongation factor G & 3.667679 \\
G7SD52 & ABC superfamily ATP binding cassette & 3.201581 \\
& transporter, membrane protein & 3.796473 \\
G5L1N9 & Nucleoid DNA-binding protein & 11.34908 \\
G7S8P5 & Phosphoglycerate kinase &
\end{tabular}

Fold change ${ }^{a}$, the ratio of different expression level between Sub-MIC tylosin treated cells and nontreated cells.

(SEM). The biofilm examination relied heavily on SEM. Because of its high magnification, the biofilm microstructure is observed clearly. These findings further confirm that S. suis can form biofilms in vitro. Although these procedures have their advantages, the TCP procedure lacks specificity and sensitivity because crystal violet stains all of the components of the biofilm and could potentially stain non-biofilm material. More specific and sensitive techniques can be performed to assess each of the individual components. This method is good for screening purposes.

Tylosin is a frequently used drug for the treatment of $S$. suis infection. Upon treatment with this antimicrobial agent, $S$. suis is inevitably exposed to a sub-inhibitory level of the agent. Therefore, we studied its effect in sub-inhibitory concentrations on S. suis biofilm formation. Tylosin can inhibit S. suis biofilm formation at sub-inhibitory concentrations in a dose-dependent manner. In addition, the inhibition of biofilm formation varied among the antimicrobial agents. Numerous reports have showed biofilm formation in the presence of sub-inhibitory concentrations of antimicrobial agents (Dunne, 1990; CarsentiEtesse et al., 1993; Rupp and Hamer, 1998; Rachid et al., 2000; Yang et al., 2015). Our results are in agreement with these previous findings. Our results showed a better activity of tylosin against $S$. suis biofilm formation. However, further studies should be conducted to confirm and clarify the relationship between the relative adherence-inhibiting properties of tylosin and their mechanisms. These results may provide information regarding the clinical use of antimicrobial agents against biofilm-forming bacteria.

Our data identified proteins related to biofilm growth that have previously been uncharacterized. iTRAQ analyses showed that the regulation of metabolism plays a key role during S. suis biofilm growth. First, the iTRAQ quantitative data revealed that carbohydrate metabolism may be particularly important during S. suis biofilm growth. It was reported that fructose bisphosphate aldolase and glyceraldehyde-3-phosphate dehydrogenase were significantly decreased in Streptococcus pneumoniae biofilms (Allan et al., 2014). In our study, there was a >two-fold increase of glyceraldehyde-3-phosphate dehydrogenase in the tylosin inhibiting biofilm formation. In addition, the levels of fructose bisphosphate aldolase (fold change: 0.62) were down-regulated. It was reported that phosphoglycerate kinase was up-regulated in S. suis biofilms compared with planktonic cells by comparative proteomic analysis (Wang et al., 2012).
Similarly, biofilms of Pseudomonas aeruginosa (Sauer et al., 2002) and Staphylococcus xylosus (Planchon et al., 2009) exhibit up-regulated phosphoglycerate kinase. There was a $>11$-fold increase in the level of phosphoglycerate kinase in the tylosin inhibiting biofilm formation. Phosphoglycerate kinase is a glycolytic enzyme that functions in the conversion of glyceraldehyde 3-phosphate into 1, 3-diphosphoglycerate. Glycolysis may play a pivotal role during $S$. suis biofilm growth. Furthermore, histidine metabolism may play an important role in biofilm formation. Histidine kinase (fold change: 1.62) was up-regulated in the tylosin-inhibited biofilm formation. Compared with other amino acids, L-His had the strongest effect on biofilm induction (Cabral et al., 2011). Histidine metabolism is also found to be involved in biofilm formation and is confirmed by gene disruption (Cabral et al., 2011). Histidine kinase is an important signaling molecule in biofilm formation in gram-positive and negative bacteria (McLoon et al., 2011; Shemesh and Chai, 2013; Yang et al., 2014; Grau et al., 2015). In addition, several ABC transporter system proteins were significantly up-regulated in the tylosin inhibiting biofilm formation. This finding is consistent with the previous results of our laboratory showing that sub-MIC erythromycin inhibits S. suis biofilm formation (Zhao et al., 2015). The carbohydrate substrate selection and fermentation determine $\mathrm{ABC}$ transporter proteins were significantly up-regulated in tylosin-treated cells, suggesting that $S$. suis had the capability of metabolizing a wide range of carbohydrates during biofilm development (Hardy et al., 2001; Marion et al., 2011; Bidossi et al., 2012; Haertel et al., 2012). Moreover, ABC transporters are important because they regulate respiration and biofilm formation, which in turn affect the rate of electricity production and bioremediation (Selvaraj et al., 2014). Furthermore, in the mutants of a pneumococcal biofilm screen, $\mathrm{ABC}$ transporters were shown to be defective in colonization (Munoz-Elias et al., 2008).

Cell surface proteins play a crucial role in biofilms. Within the biofilm, bacterial cells are embedded in a self-produced extracellular matrix. This matrix protects bacteria against a number of environmental insults. However, the matrix also confines bacterial access to fresh nutrients. Thus, the verified increase in the expression of transmembrane channels appears to be an essential requirement for the entrance of important nutrient-containing fluid (Costerton et al., 1994). In addition to acting, as channels, porins may act as potential targets for adhesion to other cells and may mediate cell attachment through binding to the proteins released for biofilm formation (Dallo et al., 2010). The outer membrane proteins may mediate cell attachment through binding to the released proteins for biofilm formation. Membrane proteins such as OmpA mediate cell adhesion in Acinetobacter baumannii (Dallo et al., 2010). The key developmental stages of biofilm development have been reported to be adhesion to surfaces, aggregation of micro colonies, and further expansion of the microbial community. The putative involvement of many genes encoding large cell surface proteins is adhesion to the epithelium and biofilm formation (Pridmore et al., 2004; Walter et al., 2005; Frese et al., 2011). Pham (Pham et al., 2010) found increased expression of outer membrane proteins in the Tannerella forsythia biofilm cells by using quantitative non-gel-based proteomic techniques. In 


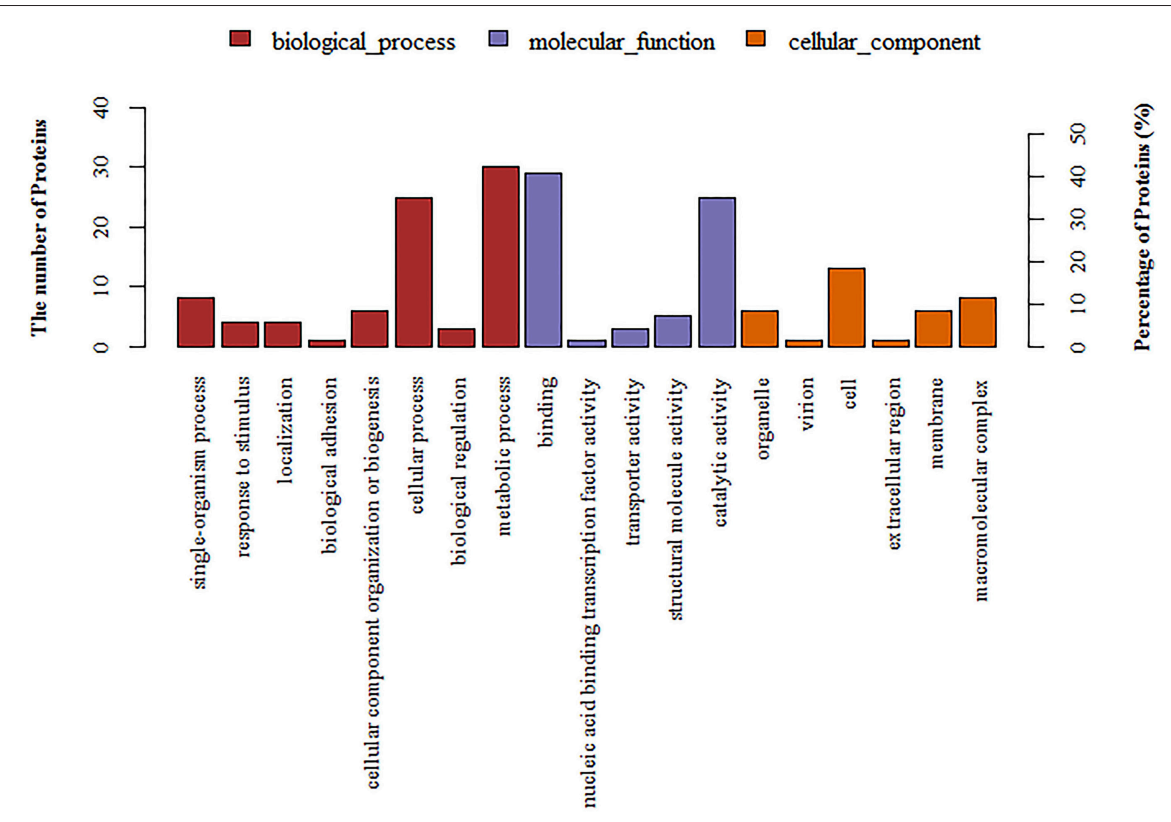

FIGURE 4 | Annotation of differentially regulated protein (ratio $>1.5$ or $<0.67$ ) functions by Gene Ontology (GO).

our study, the expression of membrane-anchored lipoprotein, phosphoglycerate kinase, sugar $\mathrm{ABC}$ transporter permease, ABC superfamily ATP binding cassette transporter membrane protein and L-fucose isomerase changed; these proteins belong to membrane proteins and cell-surface proteins and might be involved in some molecular functions including catalytic activity, motor activity, nucleotide binding, protein binding and transporter activity. For example, phosphoglycerate kinase is a S. suis surface protein that promotes cell adhesion and plays a key role in bacterial infection and invasion (Brassard et al., 2004; Wang and Lu, 2007). We predicted that these membrane proteins might affect the bacterial cell-cell interaction. Thus, membrane proteins might play a significant role in biofilm formation.

S. suis virulence proteins related to infection, persistence and competitive fitness were mostly down regulated when sub-MIC tylosin was used to inhibit biofilm formation. There was a $>1.5$ fold decrease in the level of $\mathrm{NADH}$ oxidase. NADH oxidase regulates competence, virulence, and pneumococcal persistence by its actions as an oxygen sensor, in detoxifying oxygen, and in increasing the efficiency of glucose breakdown (Auzat et al., 1999) and plays an important role in pneumococcal infection in animal models of pneumonia (Yu et al., 2001). NADH oxidase is encoded by nox. The virulence and persistence in mice of a blood isolate was attenuated by a nox insertion mutation (Auzat et al., 1999). Thus, this protein appears to be of major importance in the growth of biofilms.

\section{CONCLUSIONS}

Our study suggested that sub-MICs of tylosin could inhibit $S$. suis biofilm formation in vitro. We used a robust and reliable comparative proteomic technique (iTRAQ) to compare the abundances of proteins from 1/4 MIC of tylosin treated cells and nontreated cells. Finally, in sub-MIC tylosin inhibiting cells, we identified 96 differentially expressed proteins when the protein had a fold-change of more than a ratio $>1.5$ or $<0.67$ ( $p<0.05)$. Our proteomic data suggested general changes in metabolism (such as phosphoglycerate kinase) and surface proteins (such as $\mathrm{ABC}$ transporter proteins) involved in biofilm formation. Overall, our results indicated that $S$. suis metabolic regulation, cell-surface proteins, and virulence proteins appear to be of importance in biofilm growth by sub-MIC tylosin treatment. Thus, our data revealed the rough regulation of biofilm formation that might potentially be utilized to manage biofilm infections of $S$. suis.

\section{AUTHOR CONTRIBUTIONS}

SW the design whole experiment. YL directed the completion of the experiment. YY, YZhao, HZ, JB, JC, YZhou, CW provided help during the experiment.

\section{ACKNOWLEDGMENTS}

This work was supported by the National Natural Science Foundation of China (No. 31472231) and Guangdong Technology Research Center for Traditional Chinese Veterinary Medicine and Natural Medicine (No.20141020002). We thank Shanghai Applied Protein Technology Co. Ltd. for the help with iTRAQ.

\section{SUPPLEMENTARY MATERIAL}

The Supplementary Material for this article can be found online at: http://journal.frontiersin.org/article/10.3389/fmicb. 2016.00384 


\section{REFERENCES}

Allan, R. N., Skipp, P., Jefferies, J., Clarke, S. C., Faust, S. N., HallStoodley, L., et al. (2014). Pronounced metabolic changes in adaptation to biofilm growth by Streptococcus pneumoniae. PLoS ONE 9:e107015. doi: 10.1371/journal.pone. 0107015

Auzat, I., Chapuy-Regaud, S., Le Bras, G., Dos Santos, D., Ogunniyi, A. D., Le Thomas, I., et al. (1999). The NADH oxidase of Streptococcus pneumoniae: its involvement in competence and virulence. Mol. Microbiol. 34, 1018-1028. doi: 10.1046/j.1365-2958.1999.01663.x

Bidossi, A., Mulas, L., Decorosi, F., Colomba, L., Ricci, S., Pozzi, G., et al. (2012). A functional genomics approach to establish the complement of carbohydrate transporters in Streptococcus pneumoniae. PLoS ONE 7:e33320. doi: 10.1371/journal.pone.0033320

Bjarnsholt, T., Ciofu, O., Molin, S., Givskov, M., and Hoiby, N. (2013). Applying insights from biofilm biology to drug development - can a new approach be developed? Nat. Rev. Drug Discov. 12, 791-808. doi: 10.1038/nrd4000

Brassard, J., Gottschalk, M., and Quessy, S. (2004). Cloning and purification of the Streptococcus suis serotype 2 glyceraldehyde-3-phosphate dehydrogenase and its involvement as an adhesin. Vet. Microbiol. 102, 87-94. doi: 10.1016/j.vetmic.2004.05.008

Cabral, M. P., Soares, N. C., Aranda, J., Parreira, J. R., Rumbo, C., Poza, M., et al. (2011). Proteomic and functional analyses reveal a unique lifestyle for Acinetobacter baumannii biofilms and a key role for histidine metabolism. J. Proteome Res. 10, 3399-3417. doi: 10.1021/pr101299j

Carsenti-Etesse, H., Durant, J., Entenza, J., Mondain, V., Pradier, C., Bernard, E., et al. (1993). Effects of subinhibitory concentrations of vancomycin and teicoplanin on adherence of staphylococci to tissue culture plates. Antimicrob. Agents Chemother. 37, 921-923. doi: 10.1128/AAC.37.4.921

Costerton, J. W., Lewandowski, Z., DeBeer, D., Caldwell, D., Korber, D., and James, G. (1994). Biofilms, the customized microniche. J. Bacteriol. 176, 2137-2142.

Dallo, S. F., Denno, J., Hong, S., and Weitao, T. (2010). Adhesion of Acinetobacter baumannii to extracellular proteins detected by a live cell-protein binding assay. Ethn. Dis. 20(1 Suppl. 1):S1-7-11.

Davey, M. E., and O’Toole, G. A. (2000). Microbial biofilms: from ecology to molecular genetics. Microbiol. Mol. Biol. Rev. 64, 847-867. doi: 10.1128/MMBR.64.4.847-867.2000

Dunne, W. M. Jr. (1990). Effects of subinhibitory concentrations of vancomycin or cefamandole on biofilm production by coagulase-negative staphylococci. Antimicrob. Agents Chemother. 34, 390-393. doi: 10.1128/AAC.34.3.390

Frese, S. A., Benson, A. K., Tannock, G. W., Loach, D. M., Kim, J., Zhang, M., et al. (2011). The evolution of host specialization in the vertebrate gut symbiont Lactobacillus reuteri. PLoS Genet. 7:e1001314. doi: 10.1371/journal.pgen.1001314

Fujimura, S., Sato, T., Mikami, T., Kikuchi, T., Gomi, K., and Watanabe, A. (2008). Combined efficacy of clarithromycin plus cefazolin or vancomycin against Staphylococcus aureus biofilms formed on titanium medical devices. Int. J. Antimicrob. Agents 32, 481-484. doi: 10.1016/j.jijantimicag.2008. 06.030

Geng, H., Zhu, L., Yuan, Y., Zhang, W., Li, W., Wang, J., et al. (2008). Identification and characterization of novel immunogenic proteins of Streptococcus suis serotype 2. J. Proteome Res. 7, 4132-4142. doi: 10.1021/pr800196v

Gilbert, P., Das, J., and Foley, I. (1997). Biofilm susceptibility to antimicrobials. Adv. Dent. Res. 11, 160-167. doi: 10.1177/08959374970110010701

Gottschalk, M., Segura, M., and Xu, J. (2007). Streptococcus suis infections in humans: the Chinese experience and the situation in North America. Anim. Health Res. Rev. 8, 29-45. doi: 10.1017/S1466252307001247

Gottschalk, M., Xu, J. G., Calzas, C., and Segura, M. (2010). Streptococcus suis: a new emerging or an old neglected zoonotic pathogen? Future Microbiol. 5, 371-391. doi: 10.2217/fmb.10.2

Grau, R. R., de Ona, P., Kunert, M., Lenini, C., Gallegos-Monterrosa, R., Mhatre, E., et al. (2015). A duo of potassium-responsive histidine kinases govern the multicellular destiny of Bacillus subtilis. mBio 6:e00581-15. doi: 10.1128/mBio.00581-15

Haertel, T., Eylert, E., Schulz, C., Petruschka, L., Gierok, P., Grubmueller, S., et al. (2012). Characterization of central carbon metabolism of Streptococcus pneumoniae by isotopologue profiling. J. Biol. Chem. 287, 4260-4274. doi: 10.1074/jbc.M111.304311
Hardy, G. G., Magee, A. D., Ventura, C. L., Caimano, M. J., and Yother, J. (2001). Essential role for cellular phosphoglucomutase in virulence of type 3 Streptococcus pneumoniae. Infect. Immun. 69, 2309-2317. doi: 10.1128/IAI.69.4.2309-2317.2001

Marion, C., Aten, A. E., Woodiga, S. A., and King, S. J. (2011). Identification of an ATPase, MsmK, which energizes multiple carbohydrate ABC transporters in Streptococcus pneumoniae. Infect. Immun. 79, 4193-4200. doi: 10.1128/IAI.05290-11

Mathur, T., Singhal, S., Khan, S., Upadhyay, D. J., Fatma, T., and Rattan, A. (2006). Detection of biofilm formation among the clinical isolates of Staphylococci: an evaluation of three different screening methods. Indian J. Med. Microbiol. 24, 25-29. doi: 10.4103/0255-0857.19890

McLoon, A. L., Kolodkin-Gal, I., Rubinstein, S. M., Kolter, R., and Losick, R. (2011). Spatial regulation of histidine kinases governing biofilm formation in Bacillus subtilis. J. Bacteriol. 193, 679-685. doi: 10.1128/JB.01186-10

Munoz-Elias, E. J., Marcano, J., and Camilli, A. (2008). Isolation of Streptococcus pneumoniae biofilm mutants and their characterization during nasopharyngeal colonization. Infect. Immun. 76, 5049-5061. doi: 10.1128/IAI.00425-08

Okajima, Y., Kobayakawa, S., Tsuji, A., and Tochikubo, T. (2006). Biofilm formation by Staphylococcus epidermidis on intraocular lens material. Invest. Ophthalmol. Vis. Sci. 47, 2971-2975. doi: 10.1167/iovs.05-1172

Pham, T. K., Roy, S., Noirel, J., Douglas, I., Wright, P. C., and Stafford, G. P. (2010). A quantitative proteomic analysis of biofilm adaptation by the periodontal pathogen Tannerella forsythia. Proteomics 10, 3130-3141. doi: 10.1002/pmic.200900448

Planchon, S., Desvaux, M., Chafsey, I., Chambon, C., Leroy, S., Hebraud, M., et al. (2009). Comparative subproteome analyses of planktonic and sessile Staphylococcus xylosus C2a: new insight in cell physiology of a coagulasenegative staphylococcus in biofilm. J. Proteome Res. 8, 1797-1809. doi: $10.1021 / \mathrm{pr} 8004056$

Presterl, E., Suchomel, M., Eder, M., Reichmann, S., Lassnigg, A., Graninger, W., et al. (2007). Effects of alcohols, povidone-iodine and hydrogen peroxide on biofilms of Staphylococcus epidermidis. J. Antimicrob. Chemother. 60, 417-420. doi: $10.1093 / \mathrm{jac} / \mathrm{dkm} 221$

Pridmore, R. D., Berger, B., Desiere, F., Vilanova, D., Barretto, C., Pittet, A. C., et al. (2004). The genome sequence of the probiotic intestinal bacterium Lactobacillus johnsonii NCC 533. Proc. Natl. Acad. Sci. U.S.A. 101, 2512-2517. doi: $10.1073 /$ pnas. 0307327101

Rachid, S., Ohlsen, K., Witte, W., Hacker, J., and Ziebuhr, W. (2000). Effect of subinhibitory antibiotic concentrations on polysaccharide intercellular adhesin expression in biofilm-forming Staphylococcus epidermidis. Antimicrob. Agents Chemother. 44, 3357-3363. doi: 10.1128/AAC.44.12.3357-3363.2000

Rupp, M. E., and Hamer, K. E. (1998). Effect of subinhibitory concentrations of vancomycin, cefazolin, ofloxacin, L-ofloxacin and D-ofloxacin on adherence to intravascular catheters and biofilm formation by Staphylococcus epidermidis. J. Antimicrob. Chemother. 41, 155-161. doi: 10.1093/jac/41.2.155

Sauer, K. (2003). The genomics and proteomics of biofilm formation. Genome Biol. 4:219. doi: 10.1186/gb-2003-4-6-219

Sauer, K., Camper, A. K., Ehrlich, G. D., Costerton, J. W., and Davies, D. G. (2002). Pseudomonas aeruginosa displays multiple phenotypes during development as a biofilm. J. Bacteriol. 184, 1140-1154. doi: 10.1128/jb.184.4.1140-1154.2002

Selvaraj, A., Sumantran, V., Chowdhary, N., and Kumar, G. R. (2014). Prediction and classification of $\mathrm{ABC}$ transporters in Geobacter sulfurreducens PCA using computational approaches. Curr. Bioinform. 9, 166-172. doi: $10.2174 / 1574893608999140109113236$

Shemesh, M., and Chai, Y. (2013). A combination of glycerol and manganese promotes biofilm formation in Bacillus subtilis via histidine kinase KinD signaling. J. Bacteriol. 195, 2747-2754. doi: 10.1128/JB.00028-13

Sriskandan, S., and Slater, J. D. (2006). Invasive disease and toxic shock due to zoonotic Streptococcus suis: an emerging infection in the East? PLoS Med. 3:e187. doi: 10.1371/journal.pmed.0030187

Unwin, R. D., Griffiths, J. R., and Whetton, A. D. (2010). Simultaneous analysis of relative protein expression levels across multiple samples using iTRAQ isobaric tags with 2D nano LC-MS/MS. Nat. Protoc. 5, 1574-1582. doi: $10.1038 /$ nprot.2010.123

Walter, J., Chagnaud, P., Tannock, G. W., Loach, D. M., Dal Bello, F., Jenkinson, H. F., et al. (2005). A high-molecular-mass surface protein (Lsp) and methionine sulfoxide reductase B (MsrB) contribute to the ecological performance of 
Lactobacillus reuteri in the murine gut. Appl. Environ. Microbiol. 71, 979-986. doi: 10.1128/AEM.71.2.979-986.2005

Wang, K., and Lu, C. (2007). Adhesion activity of glyceraldehyde-3phosphate dehydrogenase in a Chinese Streptococcus suis type 2 strain. Berl. Munch. Tierarztl. Wochenschr. 120, 207-209. doi: 10.2376/0005-9366120-207

Wang, Y., Yi, L., Wu, Z., Shao, J., Liu, G., Fan, H., et al. (2012). Comparative proteomic analysis of Streptococcus suis biofilms and planktonic cells that identified biofilm infection-related immunogenic proteins. PLoS ONE 7:e33371. doi: 10.1371/journal.pone.0033371

Wang, Y., Zhang, W., Wu, Z. F., and Lu, C. P. (2011). Reduced virulence is an important characteristic of biofilm infection of Streptococcus suis. FEMS Microbiol. Lett. 316, 36-43. doi: 10.1111/j.1574-6968.2010. 02189.x

Wisniewski, J. R., Zougman, A., Nagaraj, N., and Mann, M. (2009). Universal sample preparation method for proteome analysis. Nat. Methods 6, 359-362. doi: $10.1038 /$ nmeth.1322

Yang, K., Meng, J., Huang, Y.-C., Ye, L.-H., Li, G.-J., Huang, J., et al. (2014). The role of the QseC quorum-sensing sensor kinase in epinephrine-enhanced motility and biofilm formation by Escherichia coli. Cell Biochem. Biophys. 70, 391-398. doi: 10.1007/s12013-014-9924-5

Yang, W.-Z., Yu, H.-J., Jing, H.-Q., Xu, J.-G., Chen, Z.-H., Zhu, X.-P., et al. (2006). An outbreak of human Streptococcus suis serotype 2 infections presenting with toxic shock syndrome in Sichuan, China. Zhonghua Liu Xing Bing Xue za Zhi 27, 185-191.

Yang, Y. B., Wang, S., Wang, C., Huang, Q. Y., Bai, J. W., Chen, J. Q., et al. (2015). Emodin affects biofilm formation and expression of virulence factors in Streptococcus suis ATCC700794. Arch. Microbiol. 197, 1173-1180. doi: 10.1007/s00203-015-1158-4
Yu, J., Bryant, A. P., Marra, A., Lonetto, M. A., Ingraham, K. A., Chalker, A. F., et al. (2001). Characterization of the Streptococcus pneumoniae NADH oxidase that is required for infection. Microbiology 147(Pt 2), 431-438. doi: $10.1099 / 00221287-147-2-431$

Zhang, A., Xie, C., Chen, H., and Jin, M. (2008). Identification of immunogenic cell wall-associated proteins of Streptococcus suis serotype 2. Proteomics 8, 3506-3515. doi: 10.1002/pmic.200800007

Zhang, W., and Lu, C. P. (2007a). Immunoproteomic assay of membraneassociated proteins of Streptococcus suis type 2 china vaccine strain HA9801. Zoonoses Public Health 54, 253-259. doi: 10.1111/j.1863-2378.2007.01056.x

Zhang, W., and Lu, C. P. (2007b). Immunoproteomics of extracellular proteins of Chinese virulent strains of Streptococcus suis type 2. Proteomics 7, 4468-4476. doi: 10.1002/pmic.200700294

Zhao, Y. L., Zhou, Y. H., Chen, J. Q., Huang, Q. Y., Han, Q., Liu, B., et al. (2015). Quantitative proteomic analysis of sub-MIC erythromycin inhibiting biofilm formation of S-suis in vitro. J. Proteomics 116, 1-14. doi: 10.1016/j.jprot.2014.12.019

Conflict of Interest Statement: The authors declare that the research was conducted in the absence of any commercial or financial relationships that could be construed as a potential conflict of interest.

Copyright (c) 2016 Wang, Yang, Zhao, Zhao, Bai, Chen, Zhou, Wang and Li. This is an open-access article distributed under the terms of the Creative Commons Attribution License (CC BY). The use, distribution or reproduction in other forums is permitted, provided the original author(s) or licensor are credited and that the original publication in this journal is cited, in accordance with accepted academic practice. No use, distribution or reproduction is permitted which does not comply with these terms. 